\title{
Study between anb angle and Wits appraisal in cone beam computed tomography (CBCT)
}

\author{
Natalia Zamora ${ }^{1}$, Rosa Cibrián ${ }^{2}$, Jose-Luis Gandia ${ }^{3}$, Vanessa Paredes ${ }^{4}$
}

${ }^{1} \mathrm{PhD}$, Orthodontist, Research Assistant Professor, Department of Orthodontics, Faculty of Medicine and Dentistry, University of Valencia, Valencia, Spain

${ }^{2} \mathrm{PhD}$, Associate Professor, Department of Physiology, Faculty of Medicine and Dentistry, University Valencia, Valencia, Spain ${ }^{3} \mathrm{PhD}$, Orthodontist, Professor and Department Chair of Postgraduate Orthodontics Masters Course, Department of Orthodontics, Faculty of Medicine and Dentistry, University of Valencia, Valencia, Spain

${ }^{4} \mathrm{PhD}$, Orthodontist and PhD Associate Professor, Department of Orthodontics, Faculty of Medicine and Dentistry, University of Valencia, Valencia, Spain

Correspondence:

Clínica Odontológica

Departamento Ortodoncia $5^{\circ}$ piso

c/ Gasco Oliag $n^{\circ} 1$

46010 Valencia. Spain

nataz84@hotmail.com

Zamora N, Cibrián R, Gandia JL, Paredes V. Study between anb angle
and Wits appraisal in cone beam computed tomography (CBCT). Med
Oral Patol Oral Cir Bucal. 2013 Jul 1;18 (4):e725-32.
http://www.medicinaoral.com/medoralfree01/v18i4/medoralv18i4p725.pdf

Received: $15 / 11 / 2012$

Accepted: $15 / 02 / 2013$

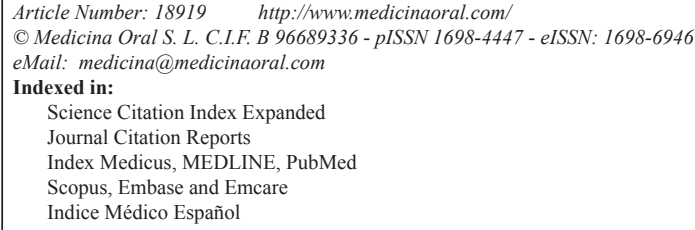

\begin{abstract}
Objectives: To analyse the ANB and Wits values and to study correlations between those two measurements and other measurements in diagnosing the anteroposterior maxilo-mandibular relationship with CBCT.

Study Design: Ninety patients who had previously a CBCT (i-CAT ${ }^{\circledR}$ ) as a diagnostic register were selected. A $3 \mathrm{D}$ cephalometry was designed using one software package, InVivo $5^{\circledR}$. This cephalometry included 3 planes of reference, 3 angle measurements and 1 linear measurement. The means and standard deviations of the mean of each measurement were assessed. After that, a Pearson's correlation coefficient has been performed to analyse the significance of each relationship.

Results: When classifying the sample according to the anteroposterior relationship, the values obtained of ANB (Class I: 53\%; Class II: 37\%; Class III: 10\%) and Wits (Class I: 35\%; Class II: 56\%; Class III: 9\%) did not coincide, except for the Class III group. However, of the patients classified differently (Class I and Class II patients) by ANB and Wits, a high percentage of individuals $(\mathrm{n}=22 ; 49 \%)$, had a mesofacial pattern with a mandibular plane angle within normal values. A correlation has been found between ANB and Wits $(\mathrm{r}=0,262)$, occlusal plane angle and ANB $(r=0,426)$, and mandibular plane angle and Wits $(r=0,242)$. No correlation was found between either Wits or ANB in relation with the age of the individuals.

Conclusions: ANB and Wits must be included in 3D cephalometric analyses as both are necessary to undertake a more accurate diagnosis of the maxillo-mandibular relationship of the patients.
\end{abstract}

Key words: Cone beam computed tomography, ANB, Wits, cephalometrics. 


\section{Introduction}

The orthodontic diagnosis of disharmonies between the skeletal bases of the cranium (1) is often undertaken by relating both the maxilla and the mandible to reference points located on the cranial base.

ANB was the cephalometric measurement most commonly used to describe the discrepancy between the skeletal bases (1). These angles logically depend on the landmarks that form them, so variations, for example, in the position of the Nasion due to growth, or due to a lack of accuracy when measuring it, can affect the relationship of the skeletal bases, affecting also de measurement of ANB (2).

Freeman (3) was one of the first authors who showed this fact, that alterations in the position of the Nasion could alter the value of the ANB angle. Later, other authors showed how the Nasion point change throughout growth adopting a more forward and upward position. They conclude, moreover, that point A was also not a fixed point, as it varied with growth in a similar way to the Nasion. Similar results were reported by Taylor (4), who stated that the ANB angle did not only depend on the Nasion, but also on facial divergence.

Oktay (1) summarised the factors that could affect the ANB angle as: the age of the patient (ANB decreases with age), the Nasion position, the rotation of the SN (Sella- Nasion) line, the occlusal plane, the maxillae and the facial prognathism.

In 1976, Jacobson (5) introduced the "Wits appraisal" (abbreviation of the University of Witwatersrand, Johannesburg. South Africa). This linear measurement analyses the antero-posterior relationship of the skeletal bases eliminating reference points on the cranial base (1). Jacobson (5) observed that when the maxilla and the mandible were related to cranial planes of reference, errors may arise as a consequence of variations in craniofacial physiognomy. Among these differences were the antero-posterior position of the Nasion with regard to the maxillae and the rotational effect of the maxillae in relation to the cranial structures of reference. Jacobson (5), explained that a high ANB in an individual with excellent occlusion could be caused by a forward position of the maxillae in relation to the Nasion and/or by a clockwise rotation of the maxillae with regard to the anterior cranial base. In these cases differences were observed between both measurements giving different values when using ANB or Wits. Furthermore, according to this author, the ANB angle was only reliable if the mandibular plane angle was normal. An increased mandibular plane would indicate a divergent pattern and, in many of these cases, an anterior cranial base with a higher inclination, which reduces the SNA angle and provides less reliable information. Likewise, the Wits value could be affected by the inclination of the occlusal plane $(1,6)$.
Various authors have recommended the use of both, ANB and Wits, for diagnosing the antero-posterior discrepancies of the skeletal bases $(3,6,7)$. Measuring values that refer to the antero-posterior relationship of the maxillae has been widely studied with conventional radiographic registers in 2D, but not in $3 \mathrm{D}$ using CBCT. This technology offers a more complete and accurate vision and measurement of all the craniofacial structures and cephalometric measurements.

Accuracy and reliability of cephalometric points has been widely studied (8-15) with CBCT, concluding the high accuracy of the CBCT systems in the spatial location of cephalometric points.

Landmarks, in 3D, are defined in the three planes of the space and can be adjusted in the different slices and views $(14,15)$, increasing its reliability more so.

This technology allows clinicians to create new reference planes. Being the planes formed by three points, instead of two (as in records 2D), the accuracy of the measurements is much greater and opens the door to reassess all the measurements previously established (15).

Moreover, different studies have compared linear and angle measurements between lateral cranial radiographs (LCR) and 3D projections (16-19) obtained from the slices of a CBCT scanner. It has been shown no clinical significance difference, it thus being possible to use most of the values or "norms" established in 2D for 3D measurements. This means we can build on standards established to date to classify our patients. However, we will consider this new technology to further refine the accuracy of the measurements.

The development and diffusion of this 3D cephalometry would be a breakthrough for the daily practice since it would not be necessary to transform data from a CBCT, with all the information that entails, to a $2 \mathrm{D}$ projection. The measurements will be made directly in the $3 \mathrm{D}$ reconstruction giving us a more realistic view of the structure that we face.

The aims of this study are to use the current 3D technology with CBCT to analyse the the ANB and Wits values and to study the correlations between those two measurements and among others when diagnosing the anteroposterior maxilo-mandibular relationship.

\section{Material and Methods}

A study approved by the ethical committee of the Clinical University Hospital of the University of Valencia was undertaken.

The final sample was composed of 90 CBCTs of patients between the ages of 8 and 40 who had previously undergone a full cranial scan at the University of Valencia, Spain. The mean age was (18.05 years \pm 8.69$)$. The CBCTs used were obtained from the data base of those patients who had previously undergone such diagnostic tool because different reasons: included teeth like ca- 
nines or third molars, agenesis or supernumerary teeth, all without moderate to severe skeletal asymmetries. No patient was scanned because of the purpose of the present study.

Each of the patients had undergone a scan using the i-CAT ${ }^{\circledR}$ (Imaging Sciences International, Hatfield, Pa) equipment. This CBCT device uses an amorphous silicon flat panel sensor to capture the fields of view (FOV). The FOV employed was the portrait mode that captures data in extended FOV mode and includes the full head of $170 \mathrm{~mm}$ in height $\times 230 \mathrm{~mm}$ in diameter with a scanning time of 8.9 seconds. It was set at medium quality and high resolution mode. It generates a total of 326 slices, with an image matrix size of $400 \times 400$. The voxel size is of $0.4 \times 0.4 \times 0.4 \mathrm{~mm}$. The focal size is $0.5 \mathrm{~mm} y$ and the size of its base is $119 \times 142 \mathrm{~cm}$. Tube voltage is $120 \mathrm{kV}$ and its intensity $23.87 \mathrm{mAs}$. The size of the data files generated is in the order of 35 megabytes.

The raw data obtained from the CBCTs were imported to the InVivo5 ${ }^{\circledR}$ software (Anatomage, San Jose, CA) which was used to visualize the slices and 3D images that are obtained from a CBCT. This is where the 3D reconstruction of the DICOM images (Digital Imaging and Communications in Medicine) is made.

Fourteen cephalometric points were defined on each of the three spatial planes $(\mathrm{X}, \mathrm{Y}, \mathrm{Z})$ (Table 1). The procedure for locating each point requires the selection of the most appropriate view (sagittal, coronal, axial) and then

Table 1. Definition of the three spatial planes of the 14 points used in this study. Anterior point (AP), anteroposterior point (APP), midpoint (MP), posterior point (PP), lowest point (LP), upper point (UP), antero-lower point (ALP).

\begin{tabular}{|c|c|c|c|c|}
\hline Landmark & Anatomical definition & $\begin{array}{l}\text { Sagittal or } \\
\text { lateral view }\end{array}$ & \begin{tabular}{|c|}
$\begin{array}{c}\text { Coronal or frontal } \\
\text { view }\end{array}$ \\
\end{tabular} & Axial view \\
\hline Sella turcica (S) & $\begin{array}{l}\text { MP of pituitary fossa of the } \\
\text { sphenoid bone }\end{array}$ & $\begin{array}{l}\text { MP of the APP } \\
\text { width }\end{array}$ & \begin{tabular}{|c|} 
MP of the lateral \\
width of the fossae, \\
determined antero- \\
posteriorly by the \\
other two slices
\end{tabular} & $\begin{array}{c}\text { MP of the APP } \\
\text { and lateral width of } \\
\text { the fossae }\end{array}$ \\
\hline Nasion $(\mathbf{N})$ & $\begin{array}{c}\text { Most AP of the frontonasal } \\
\text { suture }\end{array}$ & Most AP & MP & $\begin{array}{c}\text { Most AP and MP } \\
\text { of the anterior } \\
\text { contour }\end{array}$ \\
\hline Basion (Ba) & $\begin{array}{l}\text { Most AP of the foramen } \\
\text { magnum }\end{array}$ & Most PP and LP & $\begin{array}{c}\text { MP of the foramen, } \\
\text { determined antero- } \\
\text { posteriorly by other } \\
\text { two slices }\end{array}$ & $\begin{array}{l}\text { Most AP of the } \\
\text { foramen }\end{array}$ \\
\hline Point A (A) & $\begin{array}{c}\text { Most PP of the maxillar } \\
\text { curvature, between anterior } \\
\text { nasal spine and supradental } \\
\text { point }\end{array}$ & Most PP & $\begin{array}{c}\text { MP determined } \\
\text { antero-posteriorly by } \\
\text { the other two slices }\end{array}$ & $\mathrm{AP}$ and $\mathrm{MP}$ \\
\hline Point B (B) & $\begin{array}{l}\text { Most PP of the anterior } \\
\text { surface of the mandibular } \\
\text { symphysis }\end{array}$ & Most PP & \begin{tabular}{|c|} 
MP determined \\
antero-posteriorly by \\
the other two slices
\end{tabular} & $\mathrm{AP}$ and $\mathrm{MP}$ \\
\hline Gnathion (Gn) & $\begin{array}{l}\text { Most ALP of the mandibular } \\
\text { symphysis }\end{array}$ & Most AP and LP & MP and LP & $\mathrm{AP}, \mathrm{LP}$ and MP \\
\hline $\begin{array}{l}\text { Right and left Gonion } \\
\text { (GoR and GoL) }\end{array}$ & $\begin{array}{c}\text { Most PP of the posterior } \\
\text { edge of the ramus. Bisection } \\
\text { of two tangents: posterior } \\
\text { edge of the ramus and lower } \\
\text { part of the body }\end{array}$ & Most PP & Most PP and MP & $\begin{array}{c}\text { Most PP } \\
\text { determined } \\
\text { superoinferiorly by } \\
\text { the other two slices }\end{array}$ \\
\hline $\begin{array}{l}\text { Incisal edge of upper } \\
\text { right central incisor } \\
\text { (UIR) }\end{array}$ & $\begin{array}{l}\text { LP of the incisal edge of the } \\
\text { upper right central incisor }\end{array}$ & LP & $\begin{array}{l}\text { Most MP of the } \\
\text { mesiodistal width }\end{array}$ & Most AP and MP \\
\hline $\begin{array}{l}\text { Incisal edge of the } \\
\text { lower right central } \\
\text { incisor (LIR) }\end{array}$ & $\begin{array}{l}\text { UP of the incisal edge of the } \\
\text { lower right central incisor }\end{array}$ & UP & $\begin{array}{l}\text { Most MP of the } \\
\text { mesiodistal width }\end{array}$ & Most AP and MP \\
\hline $\begin{array}{l}\text { Upper right and left } \\
\text { 1st molar (U16, U26) }\end{array}$ & $\begin{array}{l}\text { Most PP and MP of the } \\
\text { distal surface of the first } \\
\text { upper molars }\end{array}$ & Most PP and MP & \begin{tabular}{|} 
MP determined \\
antero-posteriorly by \\
the other two slices
\end{tabular} & Most PP and MP \\
\hline $\begin{array}{c}\text { Lower right and left 1st } \\
\text { molar }(\mathrm{L} 46, \mathrm{L36})\end{array}$ & $\begin{array}{c}\text { Most PP and MP of the } \\
\text { distal surface of the first } \\
\text { lower molars }\end{array}$ & Most PP and MP & \begin{tabular}{|c|} 
MP determined \\
antero-posteriorly by \\
the other two slices
\end{tabular} & Most PP and MP \\
\hline
\end{tabular}


adjusting that point on the other views for better accuracy. Employing this location method, all the spatial positions of each point have been pinpointed on each of these axes as numerical values.

In a previous study undertaken by the same authors (15), the reproducibility and reliability in locating cephalometric points was analyzed. To assess the reproducibility on landmark location, two observers with the same background and six years of experience in the field of orthodontics located 41 landmarks at three separate times. A total of 11,070 data were processed using the 15.0 SPSS statistical package ${ }^{\circledR}$. To discover the reproducibility of the method on landmark location, an ANOVA analysis was undertaken using two factors of variation: time (t1, t2 and $\mathrm{t} 3$ ) and observers (Ob1 and Ob2) for each axis (X, Y and Z) and landmark. The order of the CBCT scans submitted to the observers were different and randomly allocated. The intraclass correlation coefficient (ICC) was calculated. The results of the study showed that both intra-and inter-observer reliability were high, both being ICC $\geq 0.99$.

Once the cephalometric points have been adapted to the $3 \mathrm{D}$ reality, that is, have been defined on each of the spatial planes $(\mathrm{X}, \mathrm{Y}, \mathrm{Z})$ and have been duly located in their correct position, the next step was to design a 3D cephalometric analysis of the maxillo-mandibular relationship and the facial pattern.

First of all, three planes of reference have been described (Fig. 1):

1. Mid-sagittal plane (XZ) (Fig. 1): vertical plane of antero-posterior reference that divides the body in two (right and left portion), defined by the points $\mathrm{N}, \mathrm{S}$ and Ba.

2. Occlusal plane (Fig. 1): plane that passes through the midpoint of the two upper and lower central incisors (URI-LRI), through the midpoint of the cuspids of the upper and lower molars of the right side and the midpoint of the cuspids of the upper and lower molars of the left side.

3. Mandibular plane (Fig. 1): plane that passes through the two Go (GoR-GoL) points and through the Gn point.

After that, 4 variables have been defined and analysed (Fig. 1):

4. ANB angle: angle formed by Nasion, A and B points. According to this measurement, the classification of the Angle Class would be distributed in the following way: Class I values of $2^{\circ} \pm 2$ (SD), Class II values $>4^{\circ}$, Class III values $<0^{\circ}$.

5. Wits Appraisal: distance between points A and B measured on the occlusal plane, as described by Jacobson (5). We have readapted this occlusal plane to the 3D reality, as described above. According to this measurement, the classification of the malocclusion would have the following distribution: Class I values of $-1 \mathrm{~mm}$ for
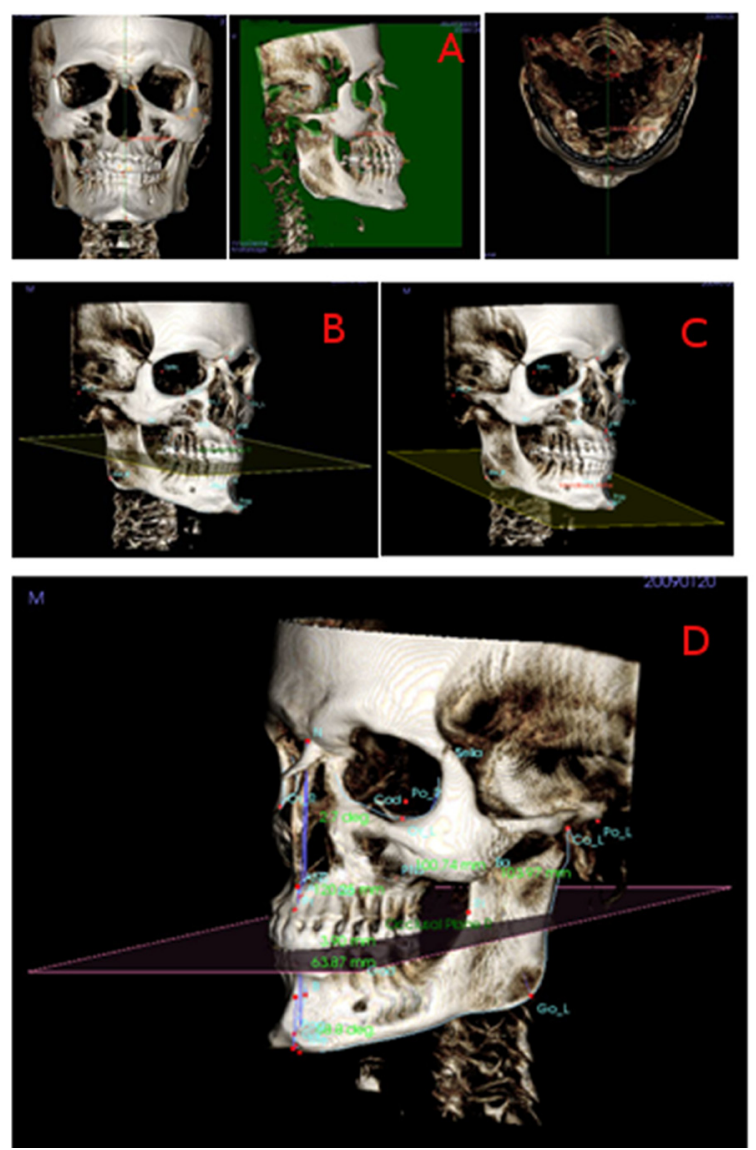

Fig. 1. View of the mid-sagittal plane (coronal, sagittal, axial), the occlusal plane, the mandibular plane, and the measurements of skeletal class with the software InVivo ${ }^{\circledR}$ (Anatomage, San Jose, CA).

men and $0 \mathrm{~mm}$ for women, Class II values $>-1 \mathrm{~mm}$ for men and values $>0 \mathrm{~mm}$ for women and Class III values $<-1 \mathrm{~mm}$ for men and values $<0 \mathrm{~mm}$ for women.

6. Occlusal plane angle: angle formed between the length of the anterior cranial base (SN) and the occlusal plane.

7. Mandibular plane angle: angle formed between the length of the anterior cranial base (SN) and the mandibular plane. Similarly to the occlusal plane, we have readapted this plane to the $3 \mathrm{D}$ reality, thus, adding more points to form the plane, as described above. According to Jacobson (5), mesofacial individuals would have values of $30^{\circ} \pm 5$ (SD) for men and $29.4^{\circ} \pm 6$ (SD) for women. Over that value, individuals present a dolichofacial pattern and below it a brachyfacial pattern, as it is a good indicator of facial pattern.

An Excel ${ }^{\circledR}$ sheet, version 12.0 for Windows (Microsoft Corporation) was created to introduce all the variables and measurements corresponding to the three dimensional cephalometric analysis of the 90 patients. The data were introduced into version 17.0 of the statistical package SPSS ${ }^{\circledR}$ for Windows (SPSS Inc., Chicago, IL) for their subsequent analysis. The previously descri- 
bed measurements were selected and the means and standard deviations of the mean (SD) of each of them were found. In addition, the Pearson's correlation coefficients were performed between the various variables described.

\section{Results}

Table 2, shows the overall mean values and standard deviation (SD) for the ANB angle, Wits Appraisal, occlusal plane and mandibular plane of all patients.

Figure 2 shows the percentages of anteroposterior relationships of the sample according to ANB and Wits Appraisal. According to the ANB angle, there would be $53 \%$ of patients with Class I, 37\% with Class II and 10\% with Class III, whereas according to Wits, there would be $35 \%$ of patients with Class I, $56 \%$ with Class II and $9 \%$ with Class III.
Another important aspect to be analysed was the facial pattern of the sample. Figure 3 shows the facial pattern of the whole sample, whereas (Fig. 3) shows the facial pattern of those patients who differ in their anteroposterior relationship depending on ANB and Wits. In figure 3 one can observe that $49 \%$ of the patients with ANBWits discrepancy have a mesofacial pattern, $32 \%$ a dolichofacial pattern and 19\%, a brachyfacial pattern.

Results of the correlations between the different measurements are seen in table 3. A certain level of correlation between the occlusal plane angle with ANB, between the mandibular plane angle with Wits and between ANB with Wits may be observed. It has also been observed that there was no correlation of either ANB or Wits in relationship with the age of the sample.

Table 2. Mean of the whole sample and standard deviation of the mean (SD) of the measurements used in this study.

\begin{tabular}{|c|c|c|}
\hline & $\begin{array}{c}\text { MEAN OF THE } \\
\text { WHOLE } \\
\text { SAMPLE }\end{array}$ & $\begin{array}{c}\text { STANDARD } \\
\text { DEVIATION (SD) } \\
\text { OF THE MEAN }\end{array}$ \\
\hline FACIAL PATTERN & & \\
\hline Oclusal plane angle & $7,11^{\circ}$ & 3,39 \\
\hline Mandibular plane angle & $30,23^{\circ}$ & 4,16 \\
\hline $\begin{array}{c}\text { ANTEROPOSTERIOR } \\
\text { RELATIONSHIP OF THE JAWS }\end{array}$ & & \\
\hline ANB & $2,99^{\circ}$ & 2,24 \\
\hline Wits appraisal & $2,24 \mathrm{~mm}$ & 3,14 \\
\hline
\end{tabular}

\section{ANB}

\section{Wits appraisal}
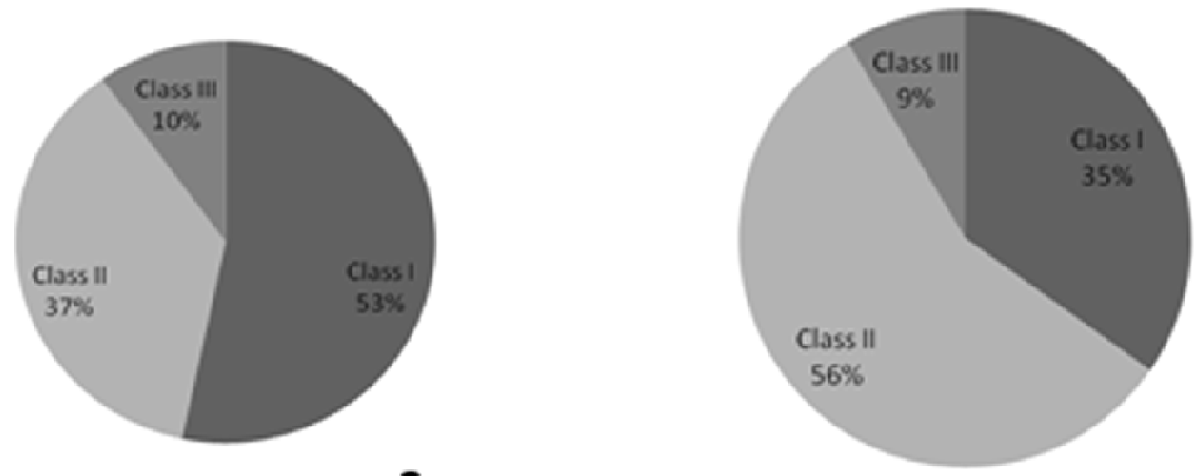

a

Fig. 2. Sample classification according to antero-posterior skeletal values, ANB and Wits appraisal. 


\section{Global Mandibular plane angle.}

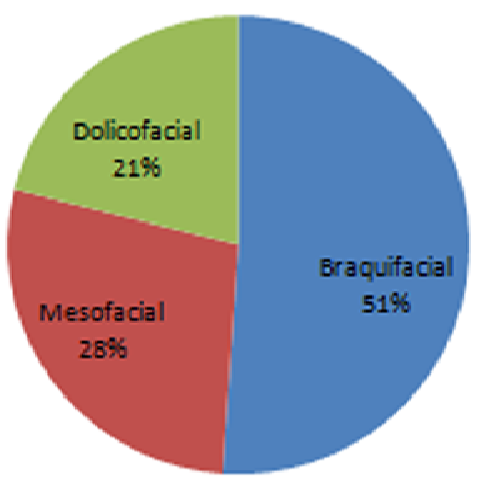

a

\section{Mandibular plane angle. Patients with ANB-Wits discrepancy}

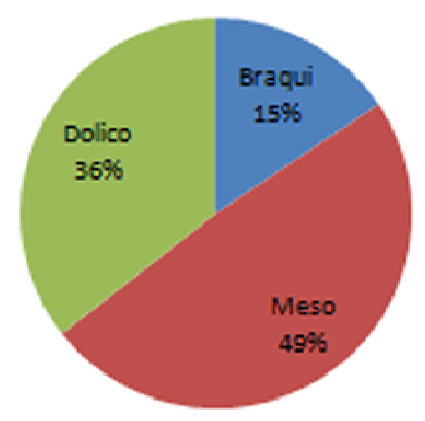

b

Fig. 3. Sample classification according to mandibular plane angle. a) Distribution of the complete sample. b) Distribution of the $50 \%$ patients who present differences between ANB and Wits.

Table 3. Correlation values.

\begin{tabular}{|c|c|c|c|c|}
\hline & Age & $\begin{array}{c}\text { Oclusal } \\
\text { Plane Angle }\end{array}$ & $\begin{array}{c}\text { Mandibular } \\
\text { Plane Angle }\end{array}$ & $\begin{array}{c}\text { Wits } \\
\text { appraisal }\end{array}$ \\
\hline ANB & 0,104 & $0,426^{* *}$ & 0,036 & $0,268^{*}$ \\
\hline Wits & 0,113 & 0,157 & $0,242^{*}$ & 1 \\
\hline
\end{tabular}

**. Significant correlation at level: 0,01 (bilateral).

*. Significant correlation at level 0,05 (bilateral).

\section{Discussion}

To carry out this study, records of patients who had previously undergone a $\mathrm{CBCT}$ as a diagnostic tool because some additional alteration (agenesis, supernumerary teeth, included teeth...) were used; so undertaking a CBCT was justified. Patients with moderate and severe asymmetries were not included in this study.
In spite of the fact that there are already many studies on this issue, radiation that CBCT systems generate must continue to be carefully studied (20), as, to date, the radiation dose involved is considerably greater than that of conventional digital radiographs and their recommended use has to be fully justified (20).

Despite the fact that the sample was large, including 90 patients, the drawback of carrying out a study of these characteristics is that irradiating patients only for research purposes is not justified, creating in some cases difficulties to properly interpret the results.

Of the 90 patients analysed in our study, there was a difference between the ANB and Wits anteroposterior classification in $50 \%$ of the cases. ANB diagnosed more patients with Class I and fewer patients with Class II, and Wits diagnosed more patients with Class II and less with Class I. However, the number of Class III diagnosed was very similar for both ANB and Wits measurements. 
Based on the results of this study, it can be seen how the anteroposterior relationship of our sample is classified differently depending on whether the ANB angle or Wits is used, especially for the class I and class II patients. These differences could appear because, as previously stated by several authors, the ANB angle is influenced by the anterior cranial base position and the possible rotation of the maxillae, whereas the Wits is influenced only by the occlusal plane, not having influence of the cranial base $(5,7)$.

On analysing the facial pattern (based on the mandibular plane) of the 45 patients for whom the Wits and ANB diagnosis of anteroposterior relationship did not coincide, we observe that half of them, 22 out of 45 (49\%), had a mesofacial pattern. This contrasts with the conclusions of Jacobson (5) who claimed that the ANB was only reliable if the mandibular plane was normal. This data indicates that, in our study, a high percentage of individuals, despite having a mesofacial pattern with a mandibular plane angle within normal values, present differences between ANB and Wits.

As regards the correlations found, our results show the highest one between occlusal plane angle and ANB $(\mathrm{r}=0,426)$. These results coincide with those of Hussels et al. (21) and Nanda (22). Moreover, these authors $(21,22)$, like us, did not find any correlation between the mandibular plane angle and the ANB.

With regard to Wits appraisal, even though some studies (23) found a correlation of Wits with the occlusal plane angle, we did not find any. However, we did find a correlation between Wits and the mandibular plane angle.

We haven't find in our study any correlation of either Wits or ANB with regard to the age of the patients. Bishara et al. (7) found a correlation between ANB and age, but not with Wits. In his study, a reduction of ANB with age was observed. Other authors $(22,24)$ have observed the same results as Bishara et al. (7) for ANB. The difference between our results and those of Bishara et al. (7) may be due to the sample selection and the way the study was undertaken, that authors (7) undertook a longitudinal study with multiple registers of each individual throughout their growth. This type of study is not possible to carry out nowadays with CBCT.

The results of our study show a slight correlation between ANB and Wits $(r=0,268)$, results similar to those of Bishara et al. (7), although the values of correlation found by that author were slightly higher than ours.

Both Bishara et al. (7) results and ours have values of correlation coefficients less than $\mathrm{r}=0.8$, meaning little predictive value when applied to an individual. Other authors $(2,22)$ also claim that, given that ANB and Wits evaluate the same skeletal discrepancy, they must, in theory, have a high correlation. However, the fact is that the correlation between them is not as strong as expec- ted, which suggests a certain weakness in at least one of the measures.

Due to the fact that the correlation between ANB and Wits is not as high as one would expect and to the fact that the position of the skeletal bases in relation to the anterior cranial base influences one measurement, but not the other, and that both measurements complement each other, both must also be included in 3D cephalometric analyses as both are necessary for undertaking, a more accurate diagnosis of the maxillo-mandibular relationship of the skeletal base and essential for individualizing each specific case.

As mentioned before (16-19), the angles and linear measurements employed in conventional 2D cephalometry could be extrapolated to 3D cephalometry. However, this 3D cephalometry provides us with a new dimension allowing us to create new planes of reference formed at least by three landmarks, and allowing us to evaluate characteristics that would be difficult to measure in 2D.

With the introduction of CBCT in orthodontic diagnosis, new possibilities have opened up in the study of cranio-facial relationships. These types of 3D analysis are going to be implemented in the future, for all the patients who need a CBCT. It is, thus, important to redefine measurements and reevaluate norms in order to diagnose the patients following also these criteria. That is why we considered of interest to create and study a sample of patients using these new technologies.

The conclusions of the present study are:

- There is no agreement between ANB and Wits in the diagnosis in $50 \%$ of the individuals of our sample.

- We have found slight correlation between ANB and Wits, a moderate correlation between the occlusal plane angle and ANB, a slight correlation between the mandibular plane angle and Wits and no correlation of either ANB or Wits with age.

\section{References}

1. Oktay H. A comparison of ANB, WITS, AF-BF, and APDI measurements. Am J Orthod Dentofacial Orthop. 1991;99:122-8.

2. Rotberg S, Fried N, Kane J, Shapiro E. Predicting the "Wits" appraisal from the ANB angle. Am J Orthod. 1980;77:636-42.

3. Freeman RS. Adjusting ANB angles to reflect the effect of maxillary position. Angle Orthod. 1981;51:162-71.

4. Taylor CM. Changes in the relationship of nasion, point $\mathrm{A}$, and point B and the effect upon ANB. Am J Orthod. 1969;56:143-63.

5. Jacobson A. Application of the "Wits" appraisal. Am J Orthod. 1976;70:179-89.

6. Iwasaki H, Ishikawa H, Chowdhury L, Nakamura S, Iida J. Properties of the ANB angle and the Wits appraisal in the skeletal estimation of Angle's Class III patients. Eur J Orthod. 2002;24:477-83.

7. Bishara SE, Fahl JA, Peterson LC. Longitudinal changes in the ANB angle and Wits appraisal: clinical implications. Am J Orthod. 1983;84:133-9.

8. Pinsky HM, Dyda S, Pinsky RW, Misch KA, Sarment DP. Accuracy of three-dimensional measurements using cone-beam CT. Dentomaxillofac Radiol. 2006;35:410-6. 
9. Moerenhout BA, Gelaude F, Swennen GR, Casselman JW, Van Der Sloten J, Mommaerts MY. Accuracy and repeatability of conebeam computed tomography (CBCT) measurements used in the determination of facial indices in the laboratory setup. J Craniomaxillofac Surg. 2009;37:18-23.

10. Lagravère MO, Carey J, Toogood RW, Major PW. Three-dimensional accuracy of measurements made with software on cone-beam computed tomography images. Am J Orthod Dentofacial Orthop. 2008;134:112-16.

11. Stratemann SA, Huang JC, Maki K, Miller AJ, Hatcher DC. Comparison of cone beam computed tomography imaging with physical measures. Dentomaxillofac Radiol. 2008;37:80-93.

12. Periago DR, Scarfe WC, Moshiri M, Scheetz JP, Silveira AM, Farman AG. Linear accuracy and reliability of cone beam CT derived 3-dimensional images constructed using an orthodontic volumetric rendering program. Angle Orthod. 2008;78:387-95.

13. Lamichane M, Anderson NK, Rigali PH, Seldin EB, Will LA. Accuracy of reconstructed images from cone-beam computed tomography scans. Am J Orthod Dentofacial Orthop. 2009;136:156-7.

14. De Oliveira AE, Cevidanes LH, Phillips C, Motta A, Burke B, Tyndall D. Observer reliability of three-dimensional cephalometric landmark identification on cone-beam computerized tomography. Oral Surg Oral Med Oral Pathol Oral Radiol Endod. 2009;107:25665.

15. Zamora N, Llamas JM, Cibrián R, Gandia JL, Paredes V. A study on the reproducibility of cephalometric landmarks when undertaking a three-dimensional (3D) cephalometric analysis. Med Oral Patol Oral Cir Bucal. 2012;17:e678-88.

16.Van Vlijmen OJ, Maal T, Bergé SJ, Bronkhorst EM, Katsaros C, Kuijpers-Jagtman AM. A comparison between 2D and 3D cephalometry on CBCT scans of human skulls. Int J Oral Maxillofac Surg. 2010;39:156-160.

17.Yitschaky O, Redlich M, Abed Y, Faerman M, Casap N, Hiller N. Comparison of common hard tissue cephalometric measurements between computed tomography $3 \mathrm{D}$ reconstruction and conventional 2D cephalometric images. Angle Orthod. 2011;81:11-6.

18. Nalçaci R, Oztürk F, Sökücü O. A comparison of two-dimensional radiography and three-dimensional computed tomography in angular cephalometric measurements. Dentomaxillofac Radiol. 2010;39:100-6.

19. Zamora N, Llamas JM, Cibrián R, Gandia JL, Paredes V. Cephalometric measurements from $3 \mathrm{D}$ reconstructed images compared with conventional 2D images. Angle Orthod. 2011;81:856-64.

20. De Vos W, Casselman J, Swennen GR. Cone-beam computerized tomography (CBCT) imaging of the oral and maxillofacial region: a systematic review of the literature. Int J of Oral and Maxillofac Surg. 2009;38:609-25.

21. Hussels W, Nanda RS. Analysis of factors affecting angle ANB. Am J Orthod. 1984;85:411-23.

22. Nanda RS. Growth changes in skeletal-facial profile and their significance in orthodontic diagnosis. Am J Orthod. 1971;59:501-13. 23. Del Santo M. Influence of occlusal plane inclination on ANB and Wits assessments of anteroposterior jaw relationships. Am J Orthod Dentofacial Orthop. 2006;129:641-8.

24. Jamison JE, Bishara SE, Peterson LC, DeKock WH, Kremenak $\mathrm{CR}$. Longitudinal changes in the maxilla and the maxillary-mandibular relationship between 8 and 17 years of age. Am J Orthod. 1982;82:217-30. 